\title{
VISUALIZATION OF SWEAT FINGERPRINTS ON VARIOUS SURFACES USING A CONJUGATED POLYELECTROLYTE
}

Joon-Hyun Yoon ${ }^{\dagger}$, Young-Jae Jin ${ }^{\dagger}$, Toshikazu Sakaguchi $^{\ddagger}$, Giseop Kwak ${ }^{\dagger *}$

${ }^{\dagger}$ School of Applied Chemical Engineering, Major in Polymer Science and Engineering, Kyungpook National University 1370 Sankyuk-dong, Buk-ku, Daegu 702-701, Korea

*E-mail: gkawk@knu.ac.kr

‡Department of Materials Science and Engineering, University of Fukui, Bunkyo, Fukui 910-8507 (Japan) 
Figure S1. Features of sebum LFPs on papers when stained using SPDPA (0.5wt\% in 1-propanol), NH $(0.79 \mathrm{wt} \%$ in acetone $)$, DFO $(0.95 w t \%$ in acetone $)$.
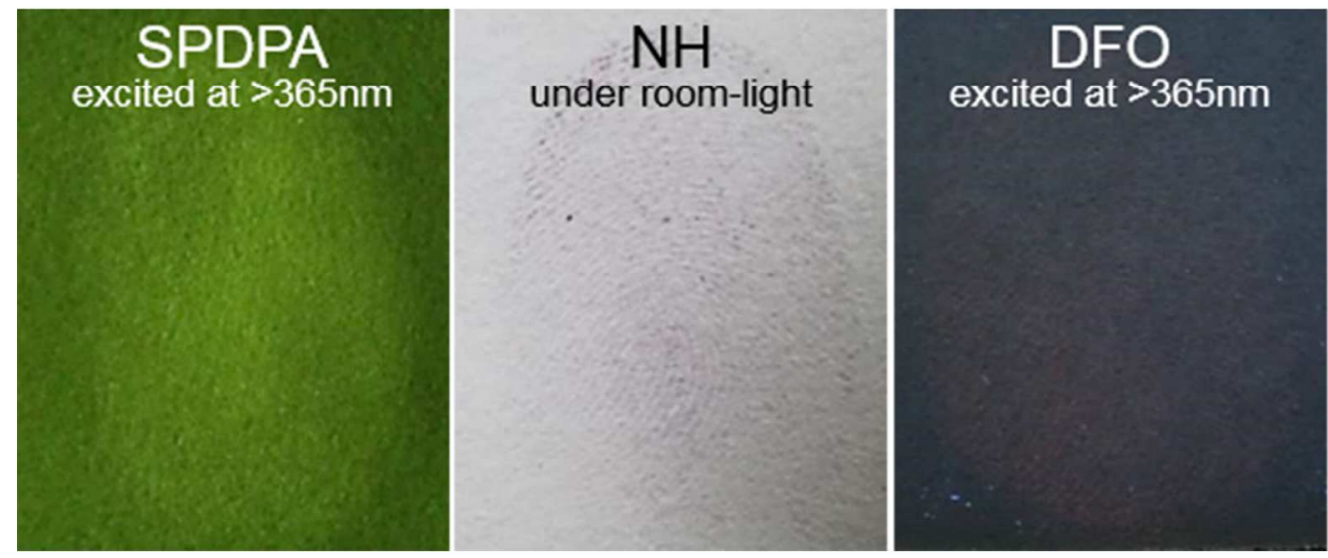

DFO

under room-light 
Figure S2. Features of LFPs from a) dried and b) cream-applied hands when stained using SPDPA (0.5wt $\%$ in 1-propanol), NH (0.79wt $\%$ in acetone), DFO $(0.95 \mathrm{wt} \%$ in acetone $)$.
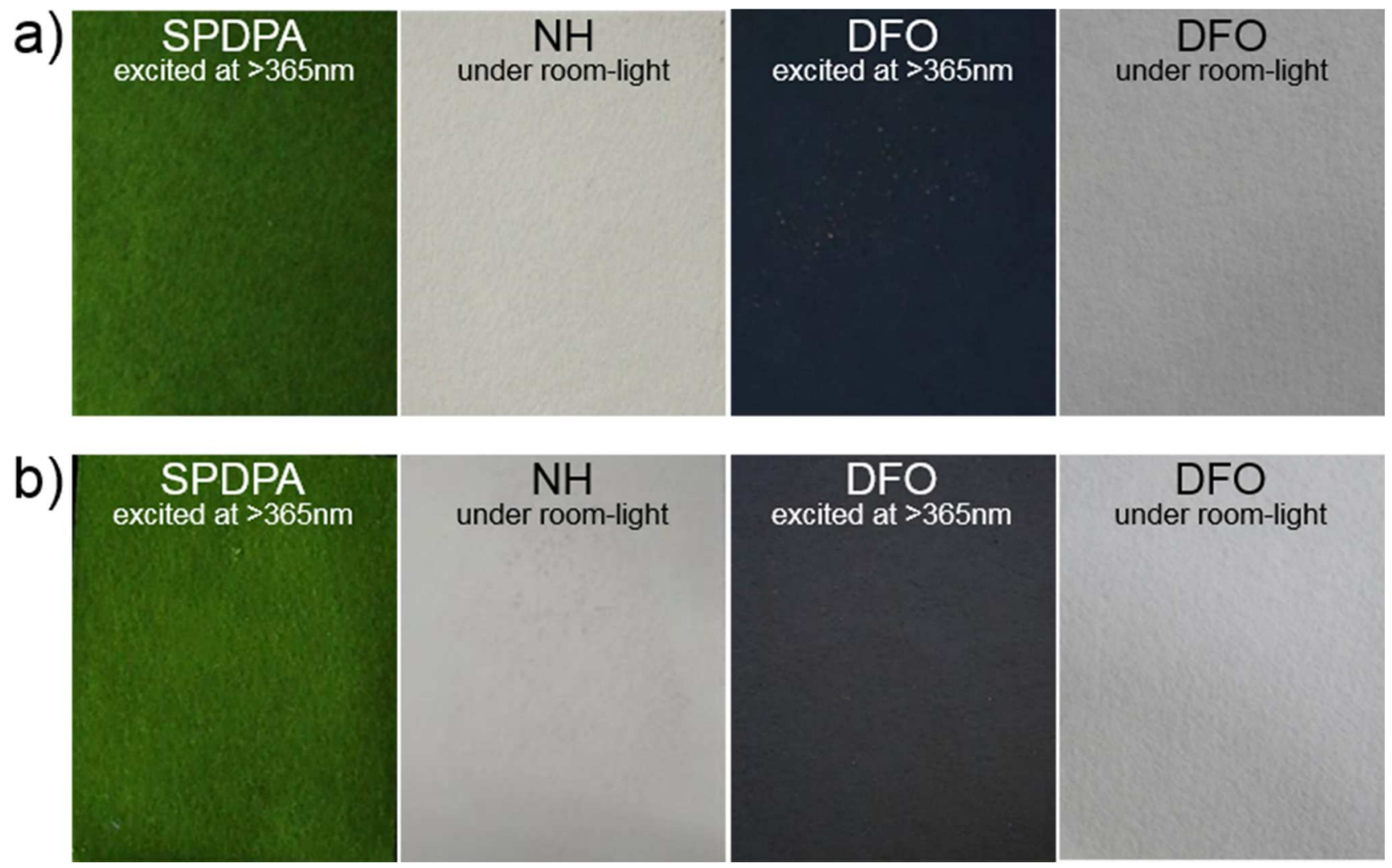
Figure S3. Features of sweat-component LFPs on glasses and plastics stained using $\mathrm{NH}(0.79 \mathrm{wt} \%$ in acetone) and DFO (0.95wt \% in acetone).
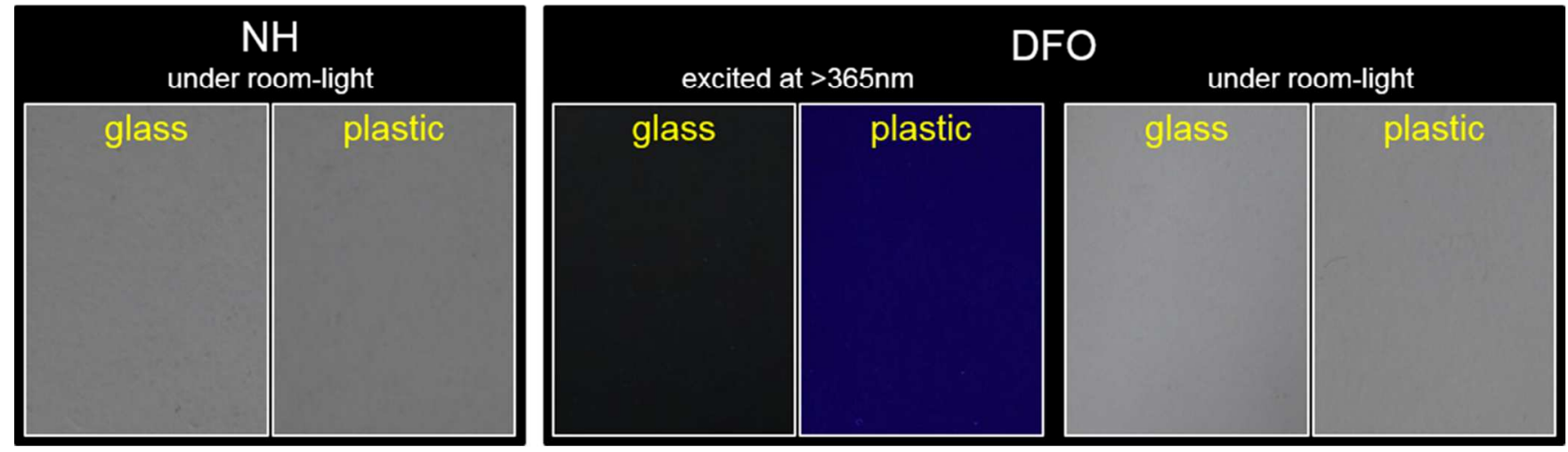